\title{
Marco Nuti, Balzac et Cézanne: l'artiste entre mythe et réalité
}

\section{Marco Stupazzoni}

\section{Q OpenEdition}

1 Journals

\section{Edizione digitale}

URL: http://journals.openedition.org/studifrancesi/6007

DOI: 10.4000/studifrancesi.6007

ISSN: 2421-5856

\section{Editore}

Rosenberg \& Sellier

\section{Edizione cartacea}

Data di pubblicazione: 1 mai 2011

Paginazione: 186

ISSN: 0039-2944

\section{Notizia bibliografica digitale}

Marco Stupazzoni, «Marco Nuti, Balzac et Cézanne: l'artiste entre mythe et réalité», Studi Francesi

[Online], 163 (LV | I) | 2011, online dal 30 novembre 2015, consultato il 08 janvier 2021. URL: http:// journals.openedition.org/studifrancesi/6007 ; DOI: https://doi.org/10.4000/studifrancesi.6007

Questo documento è stato generato automaticamente il 8 janvier 2021.

\section{(c) (i) (9)}

Studi Francesi è distribuita con Licenza Creative Commons Attribuzione - Non commerciale - Non opere derivate 4.0 Internazionale. 


\title{
Marco Nuti, Balzac et Cézanne: l'artiste entre mythe et réalité
}

\author{
Marco Stupazzoni
}

\section{NOTIZIA}

MARCO NUTI, Balzac et Cézanne: l'artiste entre mythe et réalité, in Et in pictura fabulator. Paul Cézanne et le dialogue créateur entre peinture, littérature et philosophie de Balzac à Maldiney, Fasano, Schena editore / Paris, Alain Baudry \& C éditeur, 2008, « Biblioteca della ricerca. Cultura straniera » n. 151, pp. 59-82.

1 Pubblicati tra il 1831 e il 1837, i racconti che formano la trilogia dei Romans et contes philosophiques rappresentano il momento più alto della riflessione di Balzac sull'essenza dell'arte (figurativa e musicale), oltre che sul genio e sulla verità dell'artista. In particolare, è nel Chef-d'oeuvre inconnu che Balzac, nel difendere le idee romantiche sull'arte attraverso l'opposizione tra Delacroix ed Ingres, «traite aussi du rapport de l'artiste et de l'amour» (p. 60). Incarnazione della genialità (quasi diabolica) dell'artista, Frenhofer rappresenta, per lo scrittore, una figura eccezionale, quasi magica: «le type de peintre philosophe aux frontières de la folie» (p. 65) ossessionato dall'assoluto all'interno di un contesto di isolamento e di emarginazione rispetto alla quotidianità della vita reale. Come il personaggio balzachiano, anche Cézanne «a conçu l'ambition de mener la peinture jusqu'à la perfection de son être» (p. 66), pur essendo consapevole circa le difficoltà insite in questa ricerca in relazione alla inadeguatezza dei mezzi di cui l'artista dispone. Le concordanze tra il pensiero di Frenhofer e quello di Cézanne, osserva Nuti, «sont plus remarquables quand elles concernent la définition, ou la répudiation, des moyens de la représentation» (p. 145), anche se il concetto di bellezza sostenuto da Cézanne non implica quella trascendenza dell'arte rispetto al reale che ritroviamo nel 'credo' del personaggio balzachiano. Il quadro, scrive Cézanne a E. Bernard nel settembre del 1906, non è il luogo di rivelazione di una bellezza trascendente, ma il prodotto del «développement logique de ce que nous voyons et ressentons par l'étude de la nature» (p. 81). In questo senso, le concezioni di Cézanne si 
avvicinano maggiormente al credo artistico di Porbus piuttosto che a quello di Frenhofer: tuttavia, precisa l'A. a conclusione del suo studio, «cette conjonction hypothétique» tra il racconto di Balzac e la poetica dell'arte di Cézanne suggerisce talune «affinités électives» (p. 82) che legano il pittore francese al testo balzachiano e dunque a Frenhofer, il suo personaggio centrale. 